\title{
SISTEMA INTEGRADO PARA A GESTÃO DE RECURSOS HÍDRICOS: ESTUDO DE CASO PARA A BACIA DO RIBEIRÃO ENTRE RIBEIROS
}

Michel Castro Moreira ${ }^{1}$, Fernando Falco Pruski ${ }^{2}$, André Luiz da Silva ${ }^{3}$, Demetrius David da Silva ${ }^{4}$, José Márcio Alves da Silva ${ }^{5}$

\section{RESUMO}

O valor da vazão passível de ser outorgada é influenciado pelo método utilizado para a sua obtenção, sendo que diversas metodologias encontram-se disponíveis para essa finalidade. O Sistema Integrado para a Gestão de Recursos Hídricos (SINGERH) permite obter a disponibilidade hídrica, para qualquer seção de interesse ao longo da rede hidrográfica de uma bacia, e quantificar o impacto da concessão de uma nova outorga nessa disponibilidade, tendo sido utilizado, neste trabalho, para verificar o impacto dos critérios de outorga e dos métodos de regionalização de vazões na estimativa da disponibilidade hídrica da bacia do ribeirão Entre Ribeiros. Inicialmente, foi preparada a base de dados necessária para a aplicação do SINGERH, sendo ela composta do modelo digital de elevação, das vazões mínimas e média, das equações de regionalização de vazões ,dos métodos tradicional e baseado na conservação de massas, e do cadastro de usuários de água da bacia. Os resultados obtidos indicaram a impossibilidade de concessão de novas outorgas até o final do período em análise. As simulações realizadas, além de terem permitido uma avaliação da forma como a variabilidade da disponibilidade hídrica influencia no processo de concessão de outorga, forneceu subsídios para a análise de diferentes critérios adotados para a distribuição de vazões a serem outorgadas.

Palavras-chave: outorga, vazão mínima de referência, regionalização de vazões

\section{INTEGRATED SYSTEM FOR WATER RESOURCES MANAGEMENT: CASE STUDY FOR THE BASIN OF THE ENTRE RIBEIROS CREEK}

\begin{abstract}
The value of the probably granted discharge is affected by the method used for its obtainment, and several methodologies are available to this purpose. The Integrated System for Water Resources Management (SINGERH) allows to obtaining water availability for any interesting section along the basin hydrographic net, as well as to quantify the impact from the granting of a new water right in this availability. So, it was used in this study in order to verify the impact of either grant criteria and the discharge regionalization methods upon the estimate of water availability in the basin of the Entre Rios creek. The data basis needed to the application of SINGERH was initially prepared. It consisted of digital elevation model of the minimum and medium discharges, regionalization equations of both the traditional method and that based on mass conservation and the cadastre of the basin water users. The results showed the impossibility of new grants for water using right until the end of the period under analysis. The accomplished simulations allowed to evaluate the way how variable water availability affects the water using right process, besides providing subsidies to the analysis of the different criteria adopted for the distribution of discharges to be granted.
\end{abstract}

Keywords: water right, reference discharge, discharge regionalization

\section{Recebido para publicação em 11/03/2008. Aprovado em 29/03/2010}

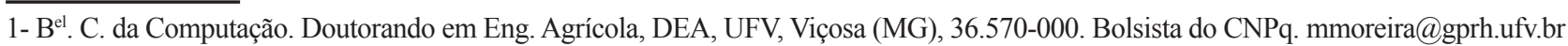

2- Eng ${ }^{\circ}$. Agrícola. Professor Titular, DEA, UFV, Viçosa (MG), 36.570-000. Bolsista do CNPq.

3- $\mathrm{B}^{\mathrm{e}}$. C. da Computação, DEA, UFV, Viçosa (MG), 36.570-000. Bolsista BDTI.

4- Eng ${ }^{\circ}$. Agrônomo. Professor Associado, DEA, UFV, Viçosa (MG), 36.570-000. Bolsista do CNPq.

5- Eng ${ }^{\circ}$. Civil. Pós-Doutorando em Eng. Agrícola, DEA, UFV, Viçosa (MG), 36.570-000. Bolsista da FAPEMIG. 
INTRODUÇÃO

Quando há baixa densidade demográfica, ocupação pouco intensiva do solo e desenvolvimento industrial restrito, o controle do uso da água em uma bacia hidrográfica exige menores cuidados. Entretanto, a medida que o seu uso se amplia e surgem conflitos, é necessária maior atenção para a proteção dos recursos hídricos, visando ao seu aproveitamento racional (SETTI et al., 2001).

A Política Nacional de Recursos Hídricos (PNRH) constitui um grande avanço na gestão dos recursos hídricos, no Brasil, tendo como preceitos básicos: a adoção da bacia hidrográfica como unidade de planejamento, a consideração dos múltiplos usos da água, o reconhecimento da água como um bem finito, vulnerável e dotado de valor econômico, e a necessidade da consideração da gestão descentralizada e participativa desse recurso (BRASIL, 1997).

Um dos instrumentos da PNRH para a gestão dos recursos hídricos é a outorga de direito de uso da água. $\mathrm{O}$ instrumento de outorga concede, por um período pré-estabelecido, o direito de uso de determinada quantidade de água, condicionado à sua disponibilidade, de tal modo que assegure ao gestor o controle quantitativo e qualitativo do seu uso, ao mesmo tempo que garante ao usuário o direito de uso da água de forma pessoal e intransferível (MOREIRA, 2006).

No Brasil, cada Estado tem adotado critérios específicos para o estabelecimento das vazões mínimas de referência para a concessão de outorga, sem, entretanto, apresentar justificativas para a adoção desses valores (CRUZ, 2001). Do mesmo modo, tem-se definido o percentual da vazão mínima de referência passível de ser outorgado. Para captações superficiais, alguns critérios adotados para outorga são apresentados no Quadro 1.

O valor da vazão passível de ser outorgada é influenciado pelo método utilizado para a sua obtenção. Segundo Tucci (2002), pelo fato de uma rede hidrométrica não cobrir todos os locais de interesse necessários ao gerenciamento dos recursos hídricos de uma região, faz-se necessária a utilização de metodologias que busquem uma melhor estimativa dos dados de interesse em seções que não possuam medições. Diversas metodologias encontram-se disponíveis para essa finalidade, sendo que, no entanto, a aplicação destas constitui uma dificuldade na quantificação da disponibilidade de água, pelo fato de estas, na maioria dos casos, necessitarem do conhecimento de informações físicas da bacia.

O desenvolvimento de programas computacionais para agilizar o processo de estudo e gestão na área de recursos hídricos tem aumentado consideravelmente (MAUD et al. 2003).

Fistarol et al. (2004) afirmam que o surgimento dos sistemas de informações de recursos hídricos ocorreu por força da necessidade de dinamizar o processo de gestão participativa, uma vez que permite contemplar a crescente complexidade dos múltiplos usos da água, forçando a melhoria da dinâmica gerencial e a oferta de serviços gerada pelo desenvolvimento tecnológico.

Moreira (2006) desenvolveu um sistema de informações de recursos hídricos, denominado Sistema Integrado para a Gestão de Recursos Hídricos (SINGERH), apresentado na primeira parte deste trabalho, que permite: obter a disponibilidade hídrica para qualquer seção de interesse ao longo da rede hidrográfica de uma bacia; quantificar o impacto da concessão de uma nova outorga nesta disponibilidade. No presente trabalho teve-se por objetivo apresentar um estudo de caso, para a subbacia do ribeirão Entre Ribeiros, afluente da bacia do rio Paracatu, que permite avaliar o desempenho do modelo desenvolvido e verificar o impacto de diferentes critérios de outorga e métodos de regionalização de vazões, na estimativa da disponibilidade hídrica de uma bacia.

\section{MATERIAL E MÉTODOS}

O estudo de caso foi realizado para a bacia do ribeirão Entre Ribeiros, sub-bacia da bacia do rio Paracatu (Figura 1). A escolha dessa bacia deu-se, principalmente, em função das constatações do intenso desenvolvimento econômico, dos conflitos pelo uso da água, já existentes e da base de dados já disponível, a qual advém dos trabalhos desenvolvidos pelo Grupo de Pesquisas em Recursos Hídricos (GPRH), da Universidade Federal de Viçosa (UFV).

Os dados utilizados, necessários para a construção do banco de dados e para aplicação do SINGERH, foram obtidos para a bacia do rio Paracatu, sendo eles: modelo digital de elevação (MDE), vazões mínimas e média, equações de regionalização de vazões dos métodos tradicional e baseado na conservação de massas e cadastro de usuários de água da bacia, os quais são descritos na sequência. 
Quadro 1. Critérios adotados para outorga de captação de águas pelos órgãos gestores de recursos hídrico

\begin{tabular}{|c|c|c|c|c|}
\hline Órgão gestor & Vazão máxima outorgável & $\begin{array}{l}\text { Legislação referente } \\
\text { à vazão máxima } \\
\text { outorgável }\end{array}$ & $\begin{array}{l}\text { Limites máximos de } \\
\text { vazões consideradas } \\
\text { insignificantes }\end{array}$ & $\begin{array}{l}\text { Legislação referente } \\
\text { à definição das } \\
\text { vazões insignificantes }\end{array}$ \\
\hline ANA & $\begin{array}{l}70 \% \text { da } \mathrm{Q}_{95} \text { podendo } \\
\text { variar em função das } \\
\text { peculiaridades de cada } \\
\text { região. } \\
20 \% \text { para cada usuário } \\
\text { individual. }\end{array}$ & $\begin{array}{c}\text { Não existe, em função } \\
\text { das peculiaridades do } \\
\text { país, podendo variar o } \\
\text { critério. }\end{array}$ & $1,0 \mathrm{~L} / \mathrm{s}$ & $\begin{array}{l}\text { Resolução ANA } \\
n^{\circ} 42 / 2004\end{array}$ \\
\hline SRH-BA & $\begin{array}{l}80 \% \text { da } \mathrm{Q}_{90} \\
20 \% \text { para cada usuário } \\
\text { individual. }\end{array}$ & $\begin{array}{l}\text { Decreto Estadual } \\
n^{\circ} 6296 / 97\end{array}$ & $0,5 \mathrm{~L} / \mathrm{s}$ & $\begin{array}{l}\text { Decreto Estadual } \\
n^{\circ} 6296 / 97\end{array}$ \\
\hline SRH-CE & $90 \%$ da $\mathrm{Q}_{90}$ reg & $\begin{array}{l}\text { Decreto Estadual } \\
\text { n }^{\circ} 23067 / 94\end{array}$ & $\begin{array}{c}2,0 \mathrm{~m}^{3} \mathrm{~h}^{-1}(0,56 \mathrm{~L} / \mathrm{s}- \\
\text { para águas superficiais } \\
\text { e subterrâneas })\end{array}$ & $\begin{array}{c}\text { Decreto Estadual } \\
\mathrm{n}^{\circ} 23067 / 94\end{array}$ \\
\hline SEMARH-GO & $70 \%$ da $Q_{95}$ & $\begin{array}{c}\text { Não possui legislação } \\
\text { específica. }\end{array}$ & $\begin{array}{l}\text { Năo estão ainda } \\
\text { definidos }\end{array}$ & - \\
\hline IGAM-MG & $\begin{array}{c}30 \% \text { da } \mathrm{Q}_{7,10} \text { para captações } \\
\text { a fio d'água. Para captações } \\
\text { em reservatórios podem ser } \\
\text { liberadas vazões superiores, } \\
\text { mantendo o mínimo residual } \\
\text { de } 70 \% \text { da } \mathrm{Q}_{7,10} \text { durante todo } \\
\text { o tempo. }\end{array}$ & $\begin{array}{l}\text { Portarias do IGAM } \\
\mathrm{n}^{\circ} 010 / 98 \text { e } 007 / 99\end{array}$ & $\begin{array}{l}1,0 \mathrm{~L} / \mathrm{s} \text { para maior } \\
\text { parte do Estado e } 0,5 \\
\mathrm{~L} / \mathrm{s} \text { para as regiões } \\
\text { de escassez (águas } \\
\text { superficiais) } \\
10,0 \mathrm{~m}^{3} \text { dia }^{-1} \text { (águas } \\
\text { subterrâneas) }\end{array}$ & $\begin{array}{l}\text { Deliberacão CERH- } \\
\text { MG nº 09/2004 }\end{array}$ \\
\hline AAGISA-PB & $\begin{array}{l}\text { 90\% da } \mathrm{Q}_{90} \text { reg. Em lagos } \\
\quad \text { territoriais, o limite } \\
\text { outorgável é reduzido em 1/3. }\end{array}$ & $\begin{array}{l}\text { Decreto Estadual } \\
\text { n }^{\circ} 19260 / 1997\end{array}$ & $\begin{array}{l}2,0 \mathrm{~m}^{3} \mathrm{~h}^{-1}(0,56 \mathrm{~L} / \mathrm{s}- \\
\text { para águas superficiais } \\
\quad \text { e subterrâneas })\end{array}$ & $\begin{array}{l}\text { Decreto Estadual } \\
\text { n }^{\circ} 19260 / 1997\end{array}$ \\
\hline SUDERHSA-PR & $50 \%$ da $Q_{95}$ & $\begin{array}{l}\text { Decreto Estadual } \\
n^{\circ} 4646 / 2001\end{array}$ & $1,0 \mathrm{~m}^{3} \mathrm{~h}^{-1}(0,3 \mathrm{~L} / \mathrm{s})$ & - \\
\hline SECTMA-PE & $\begin{array}{l}\text { Depende do risco que o } \\
\text { requerente pode assumir. }\end{array}$ & $\begin{array}{l}\text { Não existe legislação } \\
\text { específica. }\end{array}$ & $\begin{array}{l}0,5 \mathrm{~L} / \mathrm{s} \text { ou } 43 \mathrm{~m}^{3} \mathrm{dia}^{-1} \\
\text { (águas superficiais) } \\
5,0 \mathrm{~m}^{3} \text { dia }^{-1} \text { (águas } \\
\text { subterrâneas para } \\
\text { abastecimento } \\
\text { humano) }\end{array}$ & $\begin{array}{l}\text { Decreto Estadual } \\
\mathrm{n}^{\mathrm{o}} 20423 / 98\end{array}$ \\
\hline SEMAR-PI & $\begin{array}{c}80 \% \text { da } \mathrm{Q}_{95}(\text { Rios) e } 80 \% \text { da } \\
\mathrm{Q}_{90} \text { reg (Açudes) }\end{array}$ & $\begin{array}{l}\text { Não existe legislação } \\
\text { específica. }\end{array}$ & $\begin{array}{l}\text { Não estão ainda } \\
\text { definidos }\end{array}$ & 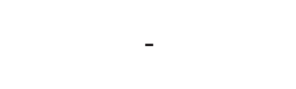 \\
\hline SERHID-RN & $90 \%$ da $\mathrm{Q}_{90}$ reg & $\begin{array}{l}\text { Decreto Estadual } \\
\mathrm{n}^{\circ} 13283 / 97\end{array}$ & $1,0 \mathrm{~m}^{3} \mathrm{~h}^{-1}(0,3 \mathrm{~L} / \mathrm{s})$ & $\begin{array}{c}\text { Decreto Estadual } \\
n^{\circ} 13283 / 97\end{array}$ \\
\hline SEMA-RS & Não está definido. & - & $\begin{array}{l}\text { Média mensal até } \\
2,0 \mathrm{~m}^{3} \text { dia }^{-1} \text { (águas } \\
\text { subterrâneas) }\end{array}$ & $\begin{array}{l}\text { Decreto Estadual } \\
\text { n }^{\circ} 42047 / 2002\end{array}$ \\
\hline DAEE-SP & $\begin{array}{l}50 \% \text { da } Q_{7,10} \text { por bacia. } \\
\text { Individualmente nunca } \\
\text { ultrapassar } 20 \% \text { da } Q_{7,10}\end{array}$ & $\begin{array}{l}\text { Não existe legislação } \\
\text { específica. }\end{array}$ & $\begin{array}{l}5,0 \mathrm{~m}^{3} \text { dia }^{-1} \text { (águas } \\
\text { subterrâneas) }\end{array}$ & $\begin{array}{l}\text { Decreto Estadual } \\
n^{\text {o } 32955 / 91}\end{array}$ \\
\hline SEPLANTEC-SE & $\begin{array}{c}100 \% \text { da } \mathrm{Q}_{90} \\
30 \% \text { da } \mathrm{Q}_{90} \text { para cada usuário } \\
\text { individual. }\end{array}$ & $\begin{array}{l}\text { Não existe legislação } \\
\text { específica. }\end{array}$ & $2,5 \mathrm{~m}^{3} \mathrm{~h}^{-1}(0,69 \mathrm{~L} / \mathrm{s})$ & Resolução no 01/2001 \\
\hline $\begin{array}{l}\text { NATURATINS- } \\
\text { TO }\end{array}$ & $\begin{array}{l}75 \% \text { da } \mathrm{Q}_{90} \text { por bacia. } \\
\text { Individualmente o máximo } \\
\text { é } 25 \% \text { da mesma } \mathrm{Q}_{90} \text {. Para } \\
\text { barragens de regularização, } \\
75 \% \text { da vazão de referência } \\
\text { adotada. }\end{array}$ & $\begin{array}{l}\text { Decreto Estadual } \\
\text { já aprovado pela } \\
\text { Câmara de outorga do } \\
\text { Conselho Estadual de } \\
\text { Recursos Hídricos. }\end{array}$ & $\begin{array}{l}0,25 \mathrm{~L} / \mathrm{s} \text { ou } 21,60 \\
\mathrm{~m}^{3} \text { dia }^{-1} \text {. A minuta } \\
\text { de regulamentação } \\
\text { aprovada deve alterar } \\
\text { para } 1,0 \mathrm{~L} / \mathrm{s} \mathrm{ou} \\
21,60 \mathrm{~m}^{3} \mathrm{dia}^{-1}\end{array}$ & $\begin{array}{c}\text { Portaria } \\
\text { NATURATINS } \\
\mathrm{n}^{\mathrm{o}} 118 / 2002\end{array}$ \\
\hline IEMA-ES & $\begin{array}{c}\text { Somatório das vazões } \\
\text { outorgadas fica limitado a } 50 \% \\
\text { da } \mathrm{Q}_{7,10} \text { para rios perenes e } \mathrm{Q}_{90} \\
\text { para rios intermitentes }\end{array}$ & $\begin{array}{c}\text { Instrução Normativa } \\
\text { No } 019 \text { - IEMA, de } 04 \\
\text { de outubro de } 2005 .\end{array}$ & $\begin{array}{l}\text { Não estão ainda } \\
\text { definidos }\end{array}$ & $\begin{array}{l}\text { Serão definidos pelo } \\
\text { CERH em Resolução } \\
\text { específica. }\end{array}$ \\
\hline
\end{tabular}

Fonte: adaptado de ANA (2005b). 


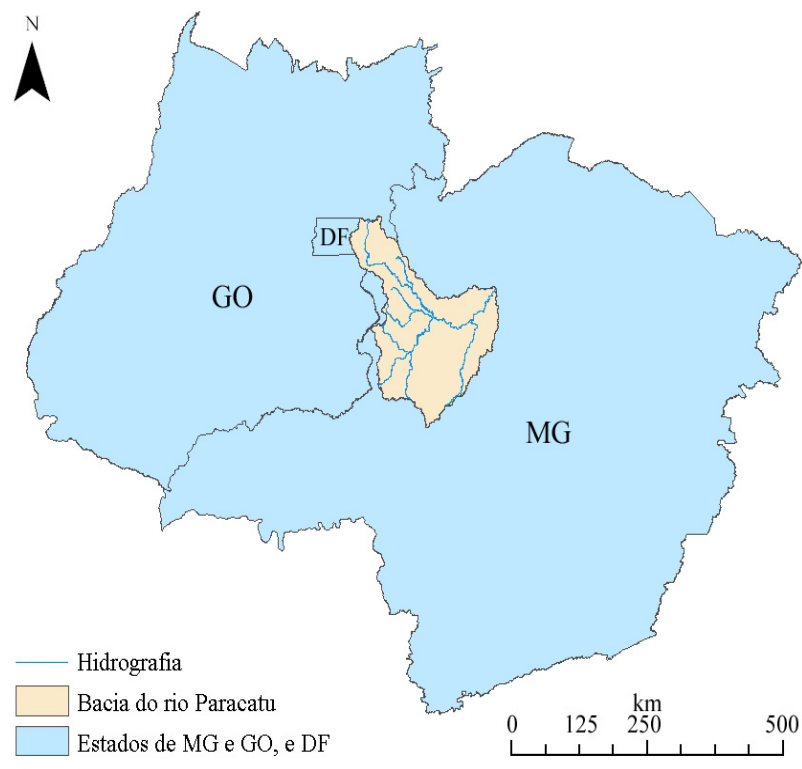

Figura 1. Mapa de localização da área em estudo.

\section{Modelo digital de elevação}

Os grids de direção de escoamento e fluxo acumulado são dados essenciais para a execução do SINGERH, sendo estes gerados a partir do MDE, utilizando rotinas comumente encontradas em softwares de Sistemas de Informações Geográficas
(SIGs).

A metodologia utilizada para a geração e validação do MDE foi concebida para ser executada em cinco etapas, conforme descritas por Chaves (2002), Baena (2002) e Pires et al. (2005), sendo estas: amostragem, pré-processamento dos dados de drenagem e elevação, geração do MDE, pós-processamento do MDE e validação do MDE.

\section{Vazões mínimas e média}

Com vistas à espacialização das vazões mínimas e média, por meio do procedimento de regionalização de vazões, foram analisados os dados consistidos, correspondentes ao período de 1970 a 2000 , de 21 estações fluviométricas (Quadro 2), pertencentes à rede hidrometeorológica da Agência Nacional de Águas (ANA), disponibilizados no Sistema de Informações Hidrológicas (HidroWeb). As áreas de drenagem das estações fluviométricas, apresentadas na Quadro 2, foram calculadas utilizando-se o MDE da bacia, após seu posicionamento a partir das suas respectivas fichas descritivas, fornecidas pela ANA, não sendo, portanto, obtidas no HidroWeb. A localização das estações fluviométricas é apresentada na Figura 2.

Quadro 2. Estações fluviométricas utilizadas no estudo

\begin{tabular}{|c|c|c|c|c|c|}
\hline Código & Estação & $\begin{array}{l}\text { Latitude } \\
\text { (Sul) }\end{array}$ & $\begin{array}{l}\text { Longitude } \\
\text { (Oeste) }\end{array}$ & $\begin{array}{c}\text { Área de } \\
\text { drenagem } \\
\left(\mathbf{k m}^{2}\right)\end{array}$ & Curso d’Água \\
\hline 42250000 & Fazenda Limoeiro & $17^{\circ} 54^{\prime} 56^{\prime \prime}$ & $47^{\circ} 00^{\prime} 38^{\prime \prime}$ & 464 & Rio Claro \\
\hline 42251000 & Fazenda Córrego do Ouro & $17^{\circ} 36^{\prime} 48^{\prime \prime}$ & $46^{\circ} 51^{\prime} 31^{\prime \prime}$ & 1836 & Rio Escuro \\
\hline 42255000 & Fazenda Nolasco & $17^{\circ} 13^{\prime} 48^{\prime \prime}$ & $47^{\circ} 01^{\prime} 20^{\prime \prime}$ & 249 & Ribeirão Santa Isabel \\
\hline 42257000 & Barra do Escurinho & $17^{\circ} 30^{\prime} 45^{\prime \prime}$ & $46^{\circ} 38^{\prime} 46^{\prime \prime}$ & 1997 & Ribeirão Escurinho \\
\hline 42290000 & Ponte da BR-040 (Paracatu) & $17^{\circ} 30^{\prime} 10^{\prime \prime}$ & $46^{\circ} 34^{\prime} 18^{\prime \prime}$ & 7744 & Rio Paracatu \\
\hline 42395000 & Santa Rosa & $17^{\circ} 15^{\prime} 19^{\prime \prime}$ & $46^{\circ} 28^{\prime} 26^{\prime \prime}$ & 12791 & Rio Paracatu \\
\hline 42435000 & Fazenda Barra da Égua & $16^{\circ} 52^{\prime} 28^{\prime \prime}$ & $46^{\circ} 35^{\prime} 12^{\prime \prime}$ & 1591 & Ribeirão Barra da Égua \\
\hline 42440000 & Fazenda Poções & $17^{\circ} 02^{\prime} 31^{\prime \prime}$ & $46^{\circ} 49^{\prime} 04^{\prime \prime}$ & 550 & Ribeirão São Pedro \\
\hline 42460000 & Fazenda Limeira & $16^{\circ} 12^{\prime} 35^{\prime \prime}$ & $47^{\circ} 13^{\prime} 58^{\prime \prime}$ & 4164 & Rio Preto \\
\hline 42490000 & Unaí & $16^{\circ} 20^{\prime} 58^{\prime \prime}$ & $46^{\circ} 52^{\prime} 48^{\prime \prime}$ & 513 & Rio Preto \\
\hline 42540000 & Santo Antônio do Boqueirão & $16^{\circ} 31^{\prime} 47^{\prime \prime}$ & $46^{\circ} 43^{\prime} 16^{\prime \prime}$ & 5.963 & Rio Preto \\
\hline 42545500 & Fazenda o Resfriado & $16^{\circ} 30^{\prime} 10^{\prime \prime}$ & $46^{\circ} 39^{\prime} 46^{\prime \prime}$ & 679 & Ribeirão Roncador \\
\hline 42546000 & Fazenda Santa Cruz & $16^{\circ} 08^{\prime} 06^{\prime \prime}$ & $46^{\circ} 44^{\prime} 52^{\prime \prime}$ & 550 & Rio Salobro \\
\hline 42600000 & Porto dos Poções & $16^{\circ} 50^{\prime} 23^{\prime \prime}$ & $46^{\circ} 21^{\prime} 26^{\prime \prime}$ & 9459 & Rio Preto \\
\hline 42690001 & Porto da Extrema & $17^{\circ} 01^{\prime} 49^{\prime \prime}$ & $46^{\circ} 00^{\prime} 49^{\prime \prime}$ & 30181 & Rio Paracatu \\
\hline 42750000 & Caatinga & $17^{\circ} 08^{\prime} 45^{\prime \prime}$ & $45^{\circ} 52^{\prime} 49^{\prime \prime}$ & 31362 & Rio Paracatu \\
\hline 42840000 & Veredas & $18^{\circ} 08^{\prime} 19^{\prime \prime}$ & $45^{\circ} 45^{\prime} 32^{\prime \prime}$ & 215 & Rio Santo Antônio \\
\hline 42850000 & Cachoeira das Almas & $17^{\circ} 21^{\prime} 02^{\prime \prime}$ & $45^{\circ} 31^{\prime} 57^{\prime \prime}$ & 4391 & Rio do Sono \\
\hline 42860000 & Cachoeira do Paredão & $17^{\circ} 07^{\prime} 16^{\prime \prime}$ & $45^{\circ} 26^{\prime} 08^{\prime \prime}$ & 5701 & Rio do Sono \\
\hline 42930000 & Porto do Cavalo & $17^{\circ} 01^{\prime} 50^{\prime \prime}$ & $45^{\circ} 32^{\prime} 22^{\prime \prime}$ & 40818 & Rio Paracatu \\
\hline 42980000 & Porto Alegre & $16^{\circ} 46^{\prime} 29^{\prime \prime}$ & $45^{\circ} 22^{\prime} 55^{\prime \prime}$ & 41481 & Rio Paracatu \\
\hline
\end{tabular}


Os dados de vazões inexistentes ou considerados inconsistentes, a partir da análise da continuidade das vazões entre os postos fluviométricos, foram atribuídos como falhas e preenchidos utilizando-se o método da regressão linear.

As vazões mínimas utilizadas no estudo foram as vazões associadas às permanências de $90\left(\mathrm{Q}_{90}\right)$ e $95 \%\left(\mathrm{Q}_{95}\right)$ e, a mínima, com sete dias de duração e período de retorno de 10 anos $\left(\mathrm{Q}_{7,10}\right)$. Os valores de $\mathrm{Q}_{90}$ e $\mathrm{Q}_{95}$ foram obtidos das curvas de permanência de cada estação fluviométrica, com base em dados diários, retratando a parcela de tempo em que determinada vazão é igualada ou superada durante o período analisado.

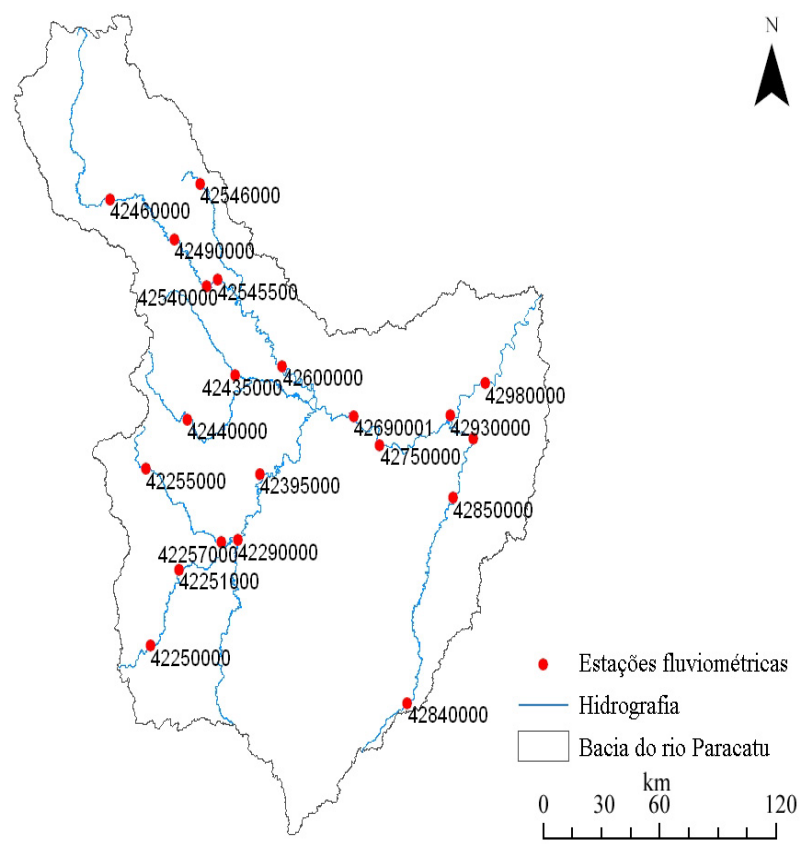

Figura 2. Localização das estações fluviométricas utilizadas no estudo.

Para a determinação da $\mathrm{Q}_{7,10}$ foi identificado, para cada ano considerado no estudo e para cada estação fluviométrica, o valor da vazão mínima pertinente à duração de sete dias $\left(\mathrm{Q}_{7}\right)$, para então estabelecer o modelo probabilístico com melhor ajuste às séries da $\mathrm{Q}_{7}$. Os modelos probabilísticos que foram analisados para representar a vazão mínima foram: Log-Normal a dois parâmetros, Log-Normal a três parâmetros, Pearson tipo III, Log-Pearson tipo III e Weibull.

A seleção da distribuição de probabilidade que melhor se ajustou aos dados da série histórica de $\mathrm{Q}_{7}$ foi realizada com base no teste de aderência de Kolmogorov-Smirnov, a diferentes níveis de probabilidade, e no coeficiente de variação. Foi escolhida a distribuição de probabilidade que apresentou significância em nível de $20 \%$ de probabilidade no teste de Kolmogorov-Smirnov, associada ao menor coeficiente de variação. Para obtenção da $Q_{7,10}$ foi utilizado o software RH 3.0 (EUCLYDES et al., 1999).

A vazão média anual de longa duração $\left(\mathrm{Q}_{\mathrm{mld}}\right)$ foi obtida para cada estação fluviométrica, pela média das vazões médias anuais.

\section{Equações de regionalização de vazões}

A obtenção das equações de regionalização de vazões pelo método tradicional, descrito em Eletrobras (1985a), foi realizada em duas etapas, que envolveram a identificação das regiões hidrologicamente homogêneas, o ajuste de regressões múltiplas entre as vazões mínimas e média e a área de drenagem da bacia.

Para a definição das regiões hidrologicamente homogêneas, foi inicialmente observada a distribuição geográfica das estações e, então, analisados os coeficientes de determinação da regressão $\left(\mathrm{r}^{2} \mathrm{e}\right.$ $\left.r^{2} a\right)$, o erro padrão (e.p), o coeficiente de variação (c.v\%), a significância do modelo pelo teste $\mathrm{F}$ $(\% \mathrm{~F})$, a classificação dos resíduos padronizados (r.p) e o erro percentual (\%d.r) entre os valores das vazões observadas e as estimadas pelo modelo de regionalização obtido.

Quando foram verificados bons resultados de $\mathrm{r}^{2}$, $r^{2} a$, e.p, c.v\%, \%F, r.p e \%d.r, a região foi definida como hidrologicamente homogênea para as vazões estudadas; entretanto, nos casos em que isso não ocorreu, houve necessidade de subdividir a região ou reorganizar as estações dentro das regiões e reiniciar o processo.

De posse dos valores de $\mathrm{Q}_{7,10}, \mathrm{Q}_{90}, \mathrm{Q}_{95}, \mathrm{Q}_{\text {mld }}$ e da área de drenagem, correspondentes às diferentes estações fluviométricas pertencentes a uma mesma região homogênea, foi aplicada a regressão múltipla entre as vazões e a área de drenagem, para obtenção das equações de regressão regionais para cada região hidrologicamente homogênea, com base nos modelos: linear, potencial, exponencial, logarítmico e recíproco.

Para fins de verificação do ajuste de determinado modelo aos dados, foram adotados o coeficiente de determinação ajustado, o erro-padrão da estimativa e o teste da função F. Os melhores modelos resultantes da aplicação da regressão múltipla foram selecionados, observando-se: maiores valores do coeficiente de determinação ajustado, menores valores de erropadrão fatorial, resultados significativos pelo teste $\mathrm{Fe}$ menor número de variáveis independentes. 
$\mathrm{Na}$ identificação das regiões hidrologicamente homogêneas e no ajuste dos modelos de regressão múltipla foi utilizado o software RH 3.0.

Apesar de não ter sido necessário obter as equações de regionalização para o método baseado na proporcionalidade de vazões específicas, descrito em Eletrobras (1985b), vale ressaltar que o SINGERH possui este método implementado para a estimativa das vazões mínimas e média.

Para a obtenção das equações de regionalização pelo método baseado na conservação de massas, proposto por Novaes (2005), ajustaram-se os modelos de regressão para representação das vazões mínimas e média em função da área de drenagem das estações fluviométricas, localizadas no rio principal e, a partir desses modelos, as vazões na foz de cada rio afluente direto do rio principal foram obtidas, procedendo-se então novos ajustes, em um processo recursivo, dos rios de maior ordem para os de menor.

$\mathrm{Na}$ Figura 3, são apresentados os rios para os quais foram realizados os ajustes, sendo que esses possuíam pelo menos uma estação fluviométrica. Nas situações em que o rio não possuía nenhum posto fluviométrico não foi necessário proceder o ajuste, já que o SINGERH obtém, automaticamente, uma equação linear, de tal forma que a equação resultante produza uma vazão nula, quando a área de drenagem é zero, e uma vazão igual à estimada na foz do rio, quando a área de drenagem é aquela correspondente à área de drenagem do rio.

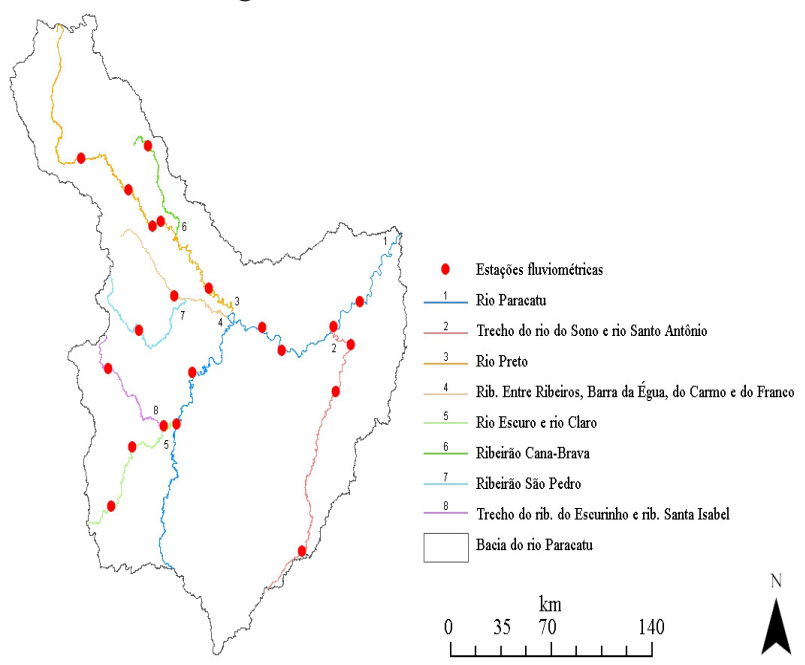

Figura 3. Rios nos quais foram ajustadas equações pelo método baseado na conservação de massas.

\section{Cadastro de usuários de água da bacia}

O SINGERH acessa as informações dos cadastros de usuários de água da bacia, em que constam as outorgas concedidas pelo órgão gestor estadual, sendo, no presente estudo, o Instituto Mineiro de Gestão das Águas (IGAM), e, pelo órgão gestor federal, a Agência Nacional de Águas (ANA).

O cadastro estadual foi disponibilizado pelo IGAM em uma versão eletrônica, do qual constam as outorgas realizadas nos rios estaduais para todo o Estado de Minas Gerais, atualizado até a data de 22 de janeiro de 2006. O cadastro federal foi disponibilizado pela ANA, também em uma versão eletrônica, no qual constam as outorgas realizadas nos rios federais de todo o país, sendo este atualizado até a data de 24 de janeiro de 2006. Pelo fato de os cadastros terem sido obtidos diretamente com os respectivos órgãos, sendo, dessa maneira, cadastro oficiais, não foi realizada análise de consistência.

Dentre as informações de cada outorga constam a localização, em coordenadas geográficas, o valor de vazão concedido e o período de vigência da outorga. De posse dessas informações, o SINGERH é capaz de calcular a disponibilidade hídrica e a vazão ainda permissível de ser outorgada, considerando os usuários a montante da seção de interesse.

\section{RESULTADOS E DISCUSSÃO}

$\mathrm{Na}$ Figura 4, apresentam-se as vazões passíveis de serem outorgadas na foz do ribeirão Entre Ribeiros (Latitude $16^{\circ} 58^{\prime} 55^{\prime \prime}$ e Longitude $46^{\circ} 14 ' 21^{\prime \prime}$ ), para o período de janeiro de 2006 a dezembro de 2010, calculadas considerando-se as outorgas concedidas até 22 de janeiro de 2006, os critérios de outorga do Estado de Minas Gerais $\left(30 \%\right.$ da $\left.\mathrm{Q}_{7,10}\right)$ e da União $\left(70 \%\right.$ da $\left.\mathrm{Q}_{95}\right)$ e as vazões estimadas pelo método tradicional.

Pela análise da Figura 4a, observa-se que, considerando-se a $\mathrm{Q}_{7,10}$ estimada pelo método tradicional e o critério de outorga do Estado de Minas Gerais (vazão máxima passível de outorga $=2,21$ $\mathrm{m}^{3} \mathrm{~s}^{-1}$ ), as vazões outorgadas, nesta seção, em todos os meses em análise, superam a vazão máxima passível de ser outorgada, fato este identificado pela cor vermelha e pelo sinal negativo dos valores. No primeiro ano em análise, verifica-se que as vazões outorgadas superam em mais de $3 \mathrm{~m}^{3} \mathrm{~s}^{-1}$ a vazão máxima passível de outorga, representando, para o mês mais crítico, uma vazão outorgada da ordem de $81,92 \%$ da $\mathrm{Q}_{7,10}$ estimada pelo método tradicional, valor este muito superior ao da máxima vazão concedida para outorga no Estado de Minas Gerais.

Percebe-se, ainda, um aumento ao longo do tempo das vazões remanescentes para concessão de 
outorga, fato este explicado pela perda de validade das outorgas vigentes.

$\mathrm{Na}$ Figura $4 b$, em que se consideram a $\mathrm{Q}_{7,10}$ estimada pelo método tradicional e o critério de outorga da União (vazão máxima passível de outorga $=7,63 \mathrm{~m}^{3} \mathrm{~s}^{-1}$ ), observa-se que em todo o ano de 2006 ainda existem vazões passíveis de serem outorgadas, sendo estas inferiores a $30 \%$ e superiores a $10 \%$ da vazão máxima passível de outorga (cor amarela). No restante do período em análise, observam-se vazões ainda passíveis de serem outorgadas, superiores a $30 \%$ da vazão máxima passível de outorga (cor verde).

A maior disponibilidade de água para concessão de outorga, evidenciada na Figura $4 \mathrm{~b}$ em relação à Figura $4 a$, decorre do fato de o critério de $70 \%$ da $\mathrm{Q}_{95}$ ser menos restritivo que o critério de $30 \%$ da $\mathrm{Q}_{7,10}$, podendo-se verificar no Quadro 1 que o critério de outorga do Estado de Minas Gerais é o mais restritivo do país. Johnson e Lopes (2003) afirmam que o critério de $30 \%$ da $\mathrm{Q}_{7,10}$ para a bacia do rio Paracatu é muito restritivo, por não representar, com exatidão, o potencial hídrico da região. O próprio IGAM, em questionário encaminhado à ANA (ANA, 2005a) salienta a necessidade da definição de diferentes critérios de outorga, conforme as particularidades de cada região do Estado.

Na Figura 5, em que são consideradas as mesmas condições aplicadas à Figura 4, utilizando-se, no entanto, as $\mathrm{Q}_{7,10}$ e $\mathrm{Q}_{95}$ estimadas pelo método baseado na conservação de massas, também se observam restrições quanto à concessão de novas outorgas para o período em análise (cor vermelha).

Evidencia-se, na Figura 5a, que no mês mais crítico (janeiro de 2006) uma vazão outorgada superior à máxima permissível para outorga no Estado de Minas Gerais, de 4,326 $\mathrm{m}^{3} \mathrm{~s}^{-1}$, representando uma vazão outorgada de $104,8 \%$ da $\mathrm{Q}_{7,10}$, estimada pelo método baseado na conservação de massas. Esta vazão outorgada, superior a 100\% da $\mathrm{Q}_{7,10}$, não implica necessariamente na eliminação total da vazão no curso d'água, uma vez que a $\mathrm{Q}_{7,10}$ corresponde a um índice probabilístico relacionado com o risco de ocorrência de um evento a cada dez anos e o valor da vazão outorgada corresponde ao somatório das outorgas, o que não implica na retirada simultânea dessas vazões. Em entrevista com técnicos do IGAM, no entanto, foi constatado que na sub-bacia do ribeirão Entre Ribeiros existem seções em que foram observadas vazões nulas, fato este que tem levado o IGAM a tomar medidas no sentido de minimizar este problema.

\begin{tabular}{|c|c|c|c|c|c|c|c|c|c|c|c|c|c|c|c|}
\hline \multicolumn{16}{|c|}{ (a) } \\
\hline & & 2006 & 2007 & 2008 & 2009 & 2010 & & & 2006 & 2007 & & 2008 & & 2009 & 2010 \\
\hline D & Jan & $-3,8440$ & $-2,833 \circ$ & -2.5390 & $-2,123 \circ$ & -1.2930 & 1 & Jan & 1.595 a & 2.606 & & 2.9 & v & $3,317 v$ & 4.146 \\
\hline & Fev & $-3,644 \circ$ & $-2.833 \circ$ & -2.5390 & $-2.123 \circ$ & $-1.293 \circ$ & & Fev & $1,795 \mathrm{a}$ & 2.606 & $v$ & 2.9 & v & $3.317 v$ & 4.146 \\
\hline & Mar & $-3.644 \circ$ & $-2.833 \circ$ & -2.5390 & $-2,122 \circ$ & $-1.293 \circ$ & & Mar & $1.795 \mathrm{a}$ & 2.606 & $v$ & 2.9 & v & $3,317 v$ & 4.146 \\
\hline & Abr & -3.5620 & $-2.783 \circ$ & $-2,539 \circ$ & -2.1220 & $-1.293 \circ$ & & Abr & 1.877 a & 2.656 & v & 2.9 & v & $3,317 v$ & 4.146 \\
\hline & Mai & $-3.516 \circ$ & $-2.783 \circ$ & $-2.539 \circ$ & $-2,057 \circ$ & $-1.293 \circ$ & & Mai & $1.923 \mathrm{a}$ & 2.656 & v & 2.9 & v & $3.382 v$ & 4.146 \\
\hline & Juח & $-3,371 \circ$ & $-2.555 \circ$ & $-2,123 \circ$ & $-2.057 \circ$ & $-1.293 \circ$ & & Jun & 2,068 a & 2.884 & v & 3,316 & v & $3,382 v$ & 4.146 \\
\hline & Jul & $-3,371 \circ$ & $-2.555 \circ$ & $-2.123 \circ$ & -2.0570 & $-1.293 \circ$ & & Jul & 2,068 a & 2.884 & v & 3.316 & v & $3,382 v$ & 4.146 \\
\hline & Aqo & $-3.371 \circ$ & $-2.539 \circ$ & -2.123 & $-1.293 \circ$ & $-1.293 \circ$ & & Aqo & 2,068 a & 2.9 & v & 3.317 & v & $4.146 v$ & $4.146 v$ \\
\hline & Set & $-3.271 \circ$ & $-2.539 \circ$ & $-2.123 \circ$ & $-1.293 \circ$ & $-1.293 \circ$ & & Set & 2,168 a & 2.9 & v & 3,317 & v & $4.146 v$ & $4.146 v$ \\
\hline & Out & -3.258 & $-2.539 \circ$ & -2.123 & $-1.293 \circ$ & $-1.293 \circ$ & & Out & 2,181 & 2.9 & $v$ & 3.317 & v & $4.146 v$ & $4.146 v$ \\
\hline & Nov & $-3.172 \circ$ & $-2.539 \circ$ & $-2.123 \circ$ & $-1.293 \circ$ & $-1.293 \circ$ & & Nov & 2,267 & 2.9 & v & 3.317 & v & $4.146 v$ & $4.146 v$ \\
\hline & Dez & $-3.156 \circ$ & $-2.539 \circ$ & $-2.123 \circ$ & $-1.293 \circ$ & $-1.293 \circ$ & & Dez & 2,283 a & 2.9 & v & 3,317 & v & $4.146 v$ & $4.146 v$ \\
\hline
\end{tabular}

Figura 4. Vazão remanescente para outorga na foz do ribeirão Entre Ribeiros, considerando o método de regionalização tradicional e os critérios de outorga: (a) $30 \%$ da $\mathrm{Q}_{7,10}$; e (b) $70 \%$ da $\mathrm{Q}_{95}$. Escala de cores: (v) verde; (a) amarelo; (1) laranja e (o) vermelho.

(a)

\begin{tabular}{|c|c|c|c|c|c|c|c|c|c|c|c|c|c|c|c|c|c|}
\hline & \multicolumn{17}{|c|}{ (a) } \\
\hline D & Jan & $-4,326 \circ$ & $-3,315$ & -3.021 & o & -2.605 & -1776 。 & 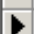 & Jan & -0.052 & 0 & 0.959 & & 1.252 & 1669 & $\mathrm{a}$ & 2498 \\
\hline & Fev & $-4.126 \circ$ & -3.315 & -3.021 & 0 & $-2,605$ & $-1.776 \circ$ & & Fev & 0,148 & 1 & 0,959 & a & 1,252 & 1,669 & a & 2.498 \\
\hline & Mar & $-4.126 \bullet$ & $-3,315$ & $-3,021$ & 0 & $-2,605$ & $-1.776 \circ$ & & Mar & 0.148 & 1 & 0,959 & a & 1,252 & 1,669 & a & 2,498 \\
\hline & Abr & $-4,044 \quad 0$ & -3.265 & -3.021 & 0 & -2.605 & -1.7760 & & Abr & 0.23 & 1 & 1,009 & a & 1,252 & 1.669 & a & 2.498 \\
\hline & Mai & $-3,998$ & -3.265 & $-3,021$ & o & $-2,54$ & $-1.776 \circ$ & & Mai & 0.276 & 1 & 1,009 & a & 1,252 & 1,734 & a & 2,498 \\
\hline & Juח & -3.853 & $-3,038$ & -2.605 & o & -2.54 & $-1.776 \quad 0$ & & Jun & 0.421 & 1 & 1,236 & a & 1.668 & 1.734 & a & 2.498 \\
\hline & Jul & $-3.853 \circ$ & $-3,038$ & $-2,605$ & 0 & $-2,54$ & $-1.776 \quad 0$ & & Jul & 0.421 & 1 & 1,236 & a & 1,668 & 1.734 & a & 2,498 \\
\hline & Aqo & $-3.853 \circ$ & -3.022 & -2.605 & o & -1.776 & $-1.776 \circ$ & & Aqo & 0.421 & 1 & 1.252 & a & $1.669 \approx$ & 2.498 & v & 2.498 \\
\hline & Set & $-3.753 \circ$ & $-3,022$ & -2.605 & o & -1.776 & $-1.776 \quad 0$ & & Set & 0,521 & 1 & 1,252 & a & 1.6698 & 2.498 & v & 2.498 \\
\hline & Out & $-3.74 \circ$ & $-3,022$ & -2.605 & a & -1.776 & $-1.776 \circ$ & & Out & 0.534 & 1 & 1,252 & a & 1,669 & 2.498 & v & 2.498 \\
\hline & Nov & $-3.654 \circ$ & $-3,022$ & -2.605 & & -1.776 & $-1.776 \circ$ & & Nov & 0,62 & a & 1,252 & & 1.669 & 2.498 & & 2,498 \\
\hline & Dez & $-3.638 \circ$ & -3.021 & -2.605 & 0 & -1.776 & $-1.776 \quad 0$ & & Dez & 0,636 & a & 1,252 & a & 1,669 & 2.498 & $v$ & 2.498 \\
\hline
\end{tabular}

Figura 5. Vazão remanescente para outorga na foz do ribeirão Entre Ribeiros, considerando o método de regionalização, baseado na conservação de massas e os critérios de outorga: (a) $30 \%$ da $\mathrm{Q}_{7,10}$; e (b) $70 \%$ da $\mathrm{Q}_{95}$. Escala de cores: (v) verde; (a) amarelo; (1) laranja e (o) vermelho. 
A situação mais crítica quanto às vazões remanescentes para concessão de novas outorgas, evidenciada na Figura $5 \mathrm{a}$ em relação à Figura $4 \mathrm{a}$, pode ser explicada pelo menor valor de $\mathrm{Q}_{7,10}$ estimado pelo método baseado na conservação de massas $\left(5,78 \mathrm{~m}^{3} \mathrm{~s}^{-1}\right)$ em relação ao método tradicional $\left(7,39 \mathrm{~m}^{3} \mathrm{~s}^{-1}\right)$.

$\mathrm{Na}$ Figura 5b, elaborada com a utilização do critério de $70 \%$ da $\mathrm{Q}_{95}$, é evidenciada, apenas no primeiro mês em análise, uma situação restritiva para concessão de novas outorgas, sendo que nos nove meses subsequentes o baixo valor da vazão remanescente (cor laranja) indica a necessidade de maior atenção na concessão de novas outorgas nesse período. No restante do período, há uma situação mais favorável quanto à existência de vazões ainda permissíveis de serem outorgadas, representada pelas cores amarela e verde no período de novembro de 2006 a dezembro de 2010.

Na Figura 6, em que são consideradas as mesmas condições aplicadas às Figuras 4 e 5, utilizando, no entanto, as $\mathrm{Q}_{7,10}$ e $\mathrm{Q}_{95}$ estimadas pelo método baseado na proporcionalidade de vazões específicas, observam-se maiores restrições quanto à concessão de novas outorgas para o período em análise.

$\mathrm{Na}$ Figura 6a verifica-se, para todo o período em análise, que foram outorgadas vazões superiores à máxima permissível no Estado de Minas Gerais, apresentando, no mês mais crítico (janeiro de 2006), uma vazão de 4,754 $\mathrm{m}^{3} \mathrm{~s}^{-1}$, o que representa uma vazão outorgada de $138,9 \%$ da $\mathrm{Q}_{7,10}$ estimada pelo método baseado na proporcionalidade de vazões específicas, para a foz do ribeirão Entre Ribeiros.

$\mathrm{Na}$ Figura $6 \mathrm{~b},\left(\mathrm{Q}_{95}\right.$ estimada pelo método baseado na proporcionalidade de vazões específicas e vazão máxima passível de outorga correspondente a $70 \% \mathrm{da}_{95}$ ), verificase, no período de janeiro de 2006 a maio de 2008, uma maior restrição quanto à concessão de novas outorgas, em relação às restrições apresentadas nas Figuras $4 \mathrm{~b}$ e $5 \mathrm{~b}$. A partir de junho de 2008 até o final do período em análise, no entanto, percebe-se que ainda existem vazões permissíveis de serem outorgadas (cores laranja e amarela).
Diversos autores também evidenciaram problemas de conflitos pelo uso da água na bacia do ribeirão Entre Ribeiros. ANA (2005b), em estudo que apresenta a relação entre a demanda e a disponibilidade hídrica de diversas bacias do país, classifica a situação desta bacia como "Preocupante", enquanto Rodriguez (2004) constatou, para a seção Fazenda Barra da Égua (localizada na bacia do ribeirão Entre Ribeiros), uma vazão de retirada pela irrigação no mês de maior demanda de $85,1 \%$ da $Q_{7,10^{*}}$.

As situações apresentadas nas Figuras 4a, 5a e 6a indicam, para a bacia do ribeirão Entre Ribeiros, a impossibilidade de concessão de novas outorgas até o final do período em análise, cabendo ao órgão gestor uma maior atenção a fim de não permitir um agravamento dos conflitos pelo uso da água. Neste sentido, o IGAM tem tomado medidas para a minimização destes conflitos, realizando um processo coletivo de outorgas, no qual as outorgas emitidas estão sendo revistas.

Tendo em vista o fato de que o critério de outorga impõe restrições à expansão do uso da água e, consequentemente, ao desenvolvimento econômico e social da região, cabe ao Estado definir políticas adequadas que otimizem a preservação ambiental e o desenvolvimento. Neste sentido, diante das situações restritivas à concessão de novas outorgas, apresentadas nas Figuras 4a, 5a e 6a, verifica-se, nas Figuras $4 b$, $5 b$ e $6 b$ que, considerando-se as vazões estimadas pelo método tradicional, a alteração do critério de outorga para $70 \%$ da $\mathrm{Q}_{95}$ criaria maior disponibilidade hídrica para a concessão de outorga, implicando, neste caso, na diminuição da vazão residual (vazão ecológica).

As simulações realizadas com o SINGERH, além de permitirem uma avaliação da forma como a variabilidade da disponibilidade hídrica influencia no processo de concessão de outorga, fornecem subsídios para a análise do desempenho de diferentes critérios adotados para a distribuição de vazões a serem outorgadas. Essas constatações reforçam a importância de se repensar o critério para estimar a disponibilidade hídrica para outorgas.

\begin{tabular}{|c|c|c|c|c|c|c|c|c|c|c|c|c|c|c|}
\hline \multicolumn{7}{|c|}{ (a) } & \multicolumn{8}{|c|}{ (b) } \\
\hline & & 2006 & 2007 & 2008 & 2009 & 2010 & & & 2006 & 2007 & 2008 & 2009 & & 2010 \\
\hline 1 & Jan & $-4.754 \circ$ & $-3.743 \circ$ & -3.4490 & $-3.033 \circ$ & $-2,203 \circ$ & $>$ & Jan & $-1.429 \circ$ & $-0,418 \quad 0$ & $-0.124 \circ$ & 0,292 & 1 & 1.121 \\
\hline & Fev & -4.554 & $-3.743 \circ$ & -3.4490 & $-3.033 \circ$ & $-2.203 \circ$ & & Fev & $-1.229 \circ$ & $-0.418 \quad \circ$ & $-0.124 \circ$ & 0,292 & 1 & 1.121 \\
\hline & Mar & $-4.554 \quad$ & $-3.743 \circ$ & $-3.449 \circ$ & $-3.032 \circ$ & $-2.203 \circ$ & & Mar & $-1.229 \quad$ & $-0.418 \quad 0$ & -0.124 & 0,292 & 1 & 1,121 a \\
\hline & Abr & $-4.472 \circ$ & $-3.693 \circ$ & -3.4490 & $-3.032 \circ$ & $-2,203 \circ$ & & Abr & $-1.147 \quad \circ$ & $-0.368 \quad \circ$ & $-0.124 \quad 0$ & 0,292 & 1 & 1.121 \\
\hline & Mai & $-4.426 \quad 0$ & $-3.693 \circ$ & -3.4490 & $-2.967 \quad$ & $-2.203 \circ$ & & Mai & $-1.101 \quad \circ$ & $-0,368 \quad 0$ & $-0.124 \circ$ & 0,357 & 1 & 1.121 \\
\hline & Juח & $-4,281 \quad$ & $-3.465 \quad 0$ & $-3.033 \circ$ & $-2,967 \quad \circ$ & $-2.203 \circ$ & & Juח & $-0.956 \quad$ & $-0,14 \quad$ & 0,292 & 0,357 & 1 & 1.121 \\
\hline & Jul & -4.281 & -3.465 a & $-3.033 \circ$ & $-2.967 \quad$ & $-2.203 \circ$ & & Jul & $-0.956 \quad \circ$ & $-0.14 \quad 0$ & 0,292 & 0,357 & 1 & 1.121 \\
\hline & Aqo & -4.281 & $-3.449 \quad 0$ & $-3.033 \circ$ & $-2,203 \circ$ & $-2.203 \circ$ & & Aqo & $-0.956 \circ$ & $-0.124 \circ$ & 0.292 & 1.121 & a & 1.121 \\
\hline & Set & $-4.181 \quad$ & $-3.449 \circ$ & $-3,033 \circ$ & $-2.203 \circ$ & $-2.203 \circ$ & & Set & $-0.856 \quad$ & $-0.124 \quad$ & 0,292 & 1.121 & a & 1.121 \\
\hline & Out & $-4.168 \quad$ & $-3.449 \circ$ & $-3,033 \circ$ & $-2,203 \circ$ & $-2,203 \circ$ & & Out & $-0.843 \circ$ & $-0.124 \circ$ & 0,292 & 1.121 & a & 1.121 \\
\hline & Nov & $-4,0820$ & $-3.449 \circ$ & -3.0330 & $-2,203 \circ$ & $-2,203 \circ$ & & Nov & $-0.757 \circ$ & $-0.124 \circ$ & 0,292 & 1.121 & a & 1.121 \\
\hline & Dez & $-4.066 \quad 0$ & $-3.449 \circ$ & -3.0330 & $-2.203 \circ$ & $-2.203 \circ$ & & Dez & $-0.741 \quad 0$ & $-0.124 \quad \circ$ & 0,292 & 1.121 & a & 1,121 a \\
\hline
\end{tabular}

Figura 6. Vazão remanescente para outorga na foz do ribeirão Entre Ribeiros, considerando o método de regionalização baseado na proporcionalidade de vazões específicas e os critérios de outorga: (a) $30 \%$ da $\mathrm{Q}_{7,10}$; e (b) $70 \%$ da $\mathrm{Q}_{95}$. Escala de cores: (v) verde; (a) amarelo; (l) laranja e (o) vermelho. 


\section{CONCLUSÕES}

Com base nos resultados obtidos, pode-se concluir que o Sistema Integrado para a Gestão de Recursos Hídricos, SINGERH, permitiu:

- Analisar o impacto dos critérios de outorga e dos métodos de regionalização de vazões na disponibilidade hídrica da sub-bacia do ribeirão Entre Ribeiros;

- Constatar a existência de conflitos pelo uso da água na sub-bacia em estudo;

- Verificar que para a situação de maior conflito a vazão outorgada representou $138,9 \%$ da $\mathrm{Q}_{7,10}$ estimada para a foz da bacia do ribeirão Entre Ribeiros;

- Verificar que, considerando-se o critério de outorga do Estado de Minas Gerais, não é possível a concessão de novas outorgas no período de janeiro de 2006 a dezembro de 2010.

\section{AGRADECIMENTOS}

Os autores agradecem à Fundação de Amparo à Pesquisa do Estado de Minas Gerais - FAPEMIG e ao Conselho Nacional de Desenvolvimento Científico e Tecnológico - CNPq, pelo apoio financeiro.

\section{REFERÊNCIAS BIBLIOGRÁFICAS}

ANA - AGÊNCIA NACIONAL DE ÁGUAS. Diagnóstico da outorga de direito de uso de recursos hídricos no país - Diretrizes e prioridades. Brasília: Agência Nacional de Águas; Ministério do Meio Ambiente, 2005a. 143 p. Disponível em: <http://www.ana.gov.br/ pnrh_novo/Tela_Apresentacao.htm $>$. Acesso em: 02/02/2006.

ANA - AGÊNCIA NACIONAL DE ÁGUAS. Disponibilidade e demandas de recursos hídricos no Brasil. Brasília: Agência Nacional de Águas; Ministério do Meio Ambiente, 2005b. 123 p. Disponível em: <http://www.ana.gov.br/pnrh_novo/ Tela_Apresentacao.htm>. Acesso em: 02 fev 2006.

BAENA, L. G. N. Regionalização de vazões para a bacia do rio Paraíba do Sul, a montante de Volta Redonda, a partir de modelo digital de elevação hidrologicamente consistente. Viçosa,
MG: UFV, 2002. 135 f. Dissertação (Mestrado em Engenharia Agrícola) - Universidade Federal de Viçosa, Viçosa. 2002.

BRASIL, Política Nacional de Recursos Hídricos. Lei $n^{0}$ 9.433, de 8 de janeiro de 1997. [S. 1.]: MMA/ SRH, 1997.

CHAVES, M. de A. Modelos digitais de elevação hidrologicamente consistentes para a bacia Amazônica. Viçosa, MG: UFV, 2002. 115 f. Tese (Doutorado em Ciência Florestal) - Universidade Federal de Viçosa, Viçosa. 2002.

CRUZ, J.C. Disponibilidade hídrica para outorga: avaliação de aspectos técnicos e conceituais. Porto Alegre, RS: UFRGS, 2001. 189 f. Tese (Doutorado em Engenharia) Universidade Federal do Rio Grande do Sul, Porto Alegre. 2001.

ELETROBRÁS. Centrais Elétricas Brasileiras S.A. Metodologia para regionalização de vazões. Rio de Janeiro, 1985a.

ELETROBRÁS. Centrais Elétricas Brasileiras S.A. Manual de minicentrais hidrelétricas. Rio de Janeiro, 1985b.

EUCLYDES, H.P.; SOUSA, E.F.; FERREIRA, P.A. RH 3.0 - Regionalização hidrológica. (Manual do programa). Viçosa, MG: UFV, DEA; Brasília, DF: MMA; Belo Horizonte, MG: RURALMINAS, 1999. 149 p.

FISTAROL, O.; FRANK, B.; REFOSCO, J.C. Sistema de Informações de Recursos Hídricos da Bacia do Itajaí. In: COBRAC 2004 CONGRESSO BRASILEIRO DE CADASTRO TÉCNICO MULTIFINALITÁRIO. Florianópolis: UFSC. Resumos... 2004. CD-Rom.

JOHNSSON, R.M.F.; LOPES, P. D. Projeto marca d'água seguindo as mudanças na gestão das bacias hidrográficas do Brasil: caderno 1 : retratos 3 x 4 das bacias pesquisadas. Brasília: Finatec, 2003. v.1. 212 p.

MAUAD, F.F., ALBERTIN, L.L. Gerenciamento integrado de quantidade e qualidade da água na bacia hidrográfica do rio Sapucaí-mirim/ grande: aplicação de simulação computacional. 
In: XV SIMPÓSIO BRASILEIRO DE RECURSOS HÍDRICOS, 2003, Curitiba-PR. Resumos..., 2003.

MOREIRA, M.C. Gestão de recursos hídricos: sistema integrado para otimização da outorga de uso da água. Viçosa, MG: UFV. 2006. 97p. Dissertação (Mestrado em Engenharia Agrícola) - Universidade Federal de Viçosa, Viçosa.

NOVAES, L.F. Modelo para a quantificação da disponibilidade hídrica na bacia do Paracatu. Viçosa, MG: UFV. 2005. 104 f. Dissertação (Mestrado em Engenharia Agrícola) - Universidade Federal de Viçosa, Viçosa.2005.

PIRES, J.M.; NASCIMENTO, M.C. do.; SANTANA, R. M.; RIBEIRO, C.A.A.S. Análise da exatidão de diferentes métodos de interpolação para geração de modelos digitais de elevação e obtenção de características morfométricas em bacias hidrográficas.

Revista Brasileira de Recursos Hídricos, Porto Alegre, v. 10, n.2, p.39-47, 2005.

RODRIGUEZ, R. del G. Metodologia para estimativa das demandas e das disponibilidades hídricas na bacia do rio Paracatu. Viçosa, MG: UFV, 2004. $94 \mathrm{f}$. Dissertação (Mestrado em Engenharia Agrícola) Universidade Federal de Viçosa, Viçosa. 2004.

SETTI, A.A.; LIMA, J.E.F.W.; CHAVES, A.G. de M.; PEREIRA, I. de C. Introdução ao gerenciamento de recursos hídricos. Brasília: Agência Nacional de Energia Elétrica Agência Nacional de Águas, 2001. 328 p.

TUCCI, C. E. M. Regionalização de vazões. Porto Alegre: Ed. Universidade: UFRGS, 2002. 256 p. 